\title{
Influence of Tomato Components in the Quantification of Four Pesticides by Gas Chromatography
}

\author{
Gevany P. Pinho, ${ }^{*, a}$ Antônio A. Neves, ${ }^{b}$ Maria Eliana L. R. Queiroz, ${ }^{b}$ \\ Flaviano O. Silvério and Deyse B. Marthe ${ }^{b}$
}

${ }^{a}$ Institute of Agricultural Sciences, Federal University of Minas Gerais, 39404-006 Montes Claros-MG, Brazil

${ }^{b}$ Department of Chemistry, Federal University of Viçosa, 36570-000 Viçosa-MG, Brazil

O efeito de matriz em análises por cromatografia gasosa é atribuído à presença de coextrativos na fase orgânica obtidos em processo de extração. Este trabalho relata o estudo da quantificação do aumento da resposta cromatográfica para quatro pesticidas em extratos orgânicos de tomate obtidos por extração sólido-líquido com purificação em baixa temperatura (ESL-PBT). Os pesticidas clorpirifós, $\lambda$-cialotrina, cipermetrina e deltametrina apresentaram aumento da resposta cromatográfica depois da saturação do sistema cromatográfico com múltiplas injeções de extrato orgânico de tomate. Verificou-se também que quanto maior o tempo de retenção, maior o efeito de matriz, e o padrão interno reduz o efeito deste, mas não o elimina. $\mathrm{O}$ efeito de matriz medido pelas curvas analíticas (em acetonitrila e extrato da matriz) foi $27 \%$ para o clorpirifós, $46 \%$ para $\lambda$-cialotrina, $96 \%$ para cipermetrina e $180 \%$ para deltametrina.

The matrix effect in gas chromatographic analysis is attributed to the presence of coextractives in organic phase obtained in the extraction process. This work reports the quantification study of increased chromatographic response of four pesticides in organic extracts of tomato extracted by solid-liquid extraction with low temperature purification (SLE-LTP). The pesticides chlorpyrifos, $\lambda$-cyhalothrin, cypermethrin and deltamethrin showed an increased chromatographic response after the saturation of the chromatographic system with multiple injections of organic extracts of tomato. It was also found that the greater the retention time, the greater the matrix effect, and that the internal standard reduces the matrix effect but does not eliminate it. The matrix effect measured by the analytical curves (in acetonitrile and matrix extract) was $27 \%$ for chlorpyrifos, $46 \%$ for $\lambda$-cyhalothrin, $96 \%$ for cypermethrin and $180 \%$ for deltamethrin.

Keywords: matrix effect, pesticide, GC/ECD, tomato, organic extract

\section{Introduction}

Pesticides are widely used in agriculture to reduce productivity losses attributed to pest attacks, ${ }^{1}$ however, the excessive use of pesticides can accumulate residues in soil, water and food. ${ }^{2,3}$ Government regulatory agencies have therefore established maximum residue levels (MRLs) of pesticides that may be found in food commodities. ${ }^{4,5}$

For monitoring and control of pesticide residue levels, accurate and precise analytical methods are required. In general, gas chromatography has stood out for its capacity of analyzing a diversity of compounds at trace $\left(\mathrm{mg} \mathrm{L}^{-1}\right)$ and ultratrace $\left(\mu \mathrm{g} \mathrm{L}^{-1}\right)$ levels. ${ }^{6}$ However,

*e-mail: gevanypp@ufmg.br during the analyses of pesticide residues in extracts of a complex matrix, endogenous components can interfere in pesticide measurements, generating "false positive" errors (impurities are eluted with the same retention time of pesticides), "false negative" errors (pesticide loss in the injection system) or even overestimated results. ${ }^{7-9}$ Overestimation of results occurs when pesticide extraction yields above $100 \%$ are obtained. Especially if pesticide standard solutions prepared in pure solvent are used during quantification since analytes can be degraded and/or adsorbed in the chromatographic system. During pesticide analysis in presence of matrix components, there is competition between pesticides and matrix components for adsorption sites in the chromatographic system. Preferential adsorption of matrix components can prevent 
degradation or favor the transfer of pesticides from the injector to the column. ${ }^{10-16}$

Among the different analyzed matrices, extracts of tomato obtained by solid-liquid extraction with low temperature purification (SLE-LTP) have being superior for providing large increases in pesticide chromatographic response. Components of this matrix showed high potential protective effects for analytes during analyses. ${ }^{17}$ But despite these facts, few works in the literature have addressed the influence of tomato components for the pesticide adsorption in the chromatographic system. ${ }^{18,19}$ Even after clean up stages of organic extracts of tomato (gel permeation chromatography, liquid-liquid extraction, matrix solid-phase dispersion etc.), coextractives still remain present (such as pigments and antioxidant phenolic compounds) due to compound miscibility with the solvent extractor. $^{20-23}$

The aim of this study was to evaluate the influence of the coextractives from tomato on gas chromatographic responses of four pesticides chlorpyrifos, $\lambda$-cyhalothrin, cypermethrin and deltamethrin (Figure 1), often detected in monitoring studies. Saturation of the gas chromatograph with organic extracts of tomato, calibration curve in solvent and calibration curve in matrix-matching were used to quantify the matrix effects.

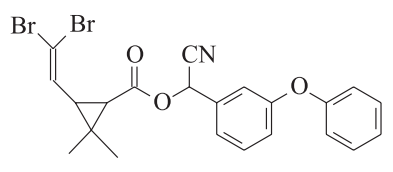

Deltamethrin

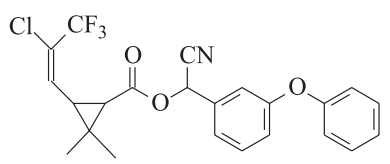

$\lambda$-Cyhalothrin

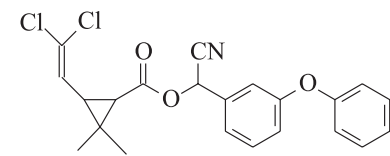

Cypermethrin

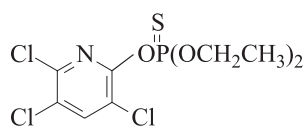

Chlorpyrifos
Figure 1. Molecular structures of the studied pesticides.

\section{Experimental}

\section{Reagents}

Stock standard solutions of chlorpyrifos (99.0\% purity), cypermethrin (92.4\%) and deltamethrin (99.0\%) purchased from Chem Service (West Chester, PA, USA) and $\lambda$-cyhalothrin $(86.5 \%)$ from Syngenta (São Paulo, Brazil) were prepared in acetonitrile with concentrations of $500 \mathrm{mg} \mathrm{L}^{-1}$ and stored at $4{ }^{\circ} \mathrm{C}$. In the same solvent, a solution containing the four pesticides was prepared at concentrations of $50 \mathrm{mg} \mathrm{L}^{-1}$ using dilutions from the stock solutions. A $50 \mathrm{mg} \mathrm{L}^{-1}$ bifenthrin solution (92.2\%, FMC, Brazil) was similarly prepared and used as an internal standard.

Ethyl acetate (Merck, Darmstadt, Germany) and HPLC (high-performance liquid chromatography) grade acetonitrile (Mallinckrodt Baker, Paris, France) were used as solvent for trace analyses. Anhydrous sodium sulfate (purity greater than 99\%) was purchased from Vetec (Rio de Janeiro, Brazil).

\section{Laboratory equipment}

A Unique ultra-sonic batch (São Paulo, Brazil) $(50 \mathrm{kHz}$, $150 \mathrm{~W}$ ) was used for sample preparation and a UV-Visible U-1100 Spectrophotometer (Hitachi) for the analyses.

\section{GC-ECD}

A Shimadzu (GC-17-A) gas chromatograph was utilized, equipped with an electron capture detector (ECD) and a HP-5 capillary column (Agilent Technologies), stationary phase of 5\% phenyl and $95 \%$ dimethylsiloxane (30 $\mathrm{m} \times 0.25 \mathrm{~mm}$ i.d., $0.1 \mu \mathrm{m}$ film thickness). Nitrogen (99.999\% purity) was used as carrier gas at a flow rate of $1.2 \mathrm{~mL} \mathrm{~min}^{-1}$ and make up gas of $29 \mathrm{ml} \mathrm{min}^{-1}$. To evaluate the matrix effect on pesticide analyses in tomatoes, the chromatographic conditions were: the split/ splitless injector was kept at $280{ }^{\circ} \mathrm{C}$, column initially at $150{ }^{\circ} \mathrm{C}$ and heated at a rate of $10{ }^{\circ} \mathrm{C} \mathrm{min}^{-1}$ to $290{ }^{\circ} \mathrm{C}$ and held for $1 \mathrm{~min}$. The detector temperature was $300{ }^{\circ} \mathrm{C}$, with $1 \mu \mathrm{L}$ of sample manually injected into the gas chromatograph with split ratio set at 1:5. Detection of pesticides was accomplished using software Workstation Class-CR10.

\section{Analytical procedure}

Samples of pesticide-free hydroponic tomatoes purchased from local retail stores in Viçosa City (Minas Gerais State, Brazil) were crushed in the laboratory. A mount of $4 \mathrm{~g}$ of the tomato pulp was transferred to a $22 \mathrm{~mL}$ transparent glass flask and an extraction mixture consisting of $8.0 \mathrm{~mL}$ acetonitrile, $1.5 \mathrm{~mL}$ ethyl acetate and $0.5 \mathrm{~mL}$ water was added. ${ }^{24}$ The system was homogenized in an ultrasonic bath for $10 \mathrm{~min}$ and chilled in a freezer at $-20{ }^{\circ} \mathrm{C}$ for $6 \mathrm{~h}$. After phase separation by freezing the aqueous phase and tomato pulp, the liquid supernatant was filtered through a $1.50 \mathrm{~g}$ layer of anhydrous sodium sulfate. The obtained filtrate (extract) was recovered in a $10 \mathrm{~mL}$ volumetric flask with acetonitrile and stored in the freezer until analysis by GC-ECD. ${ }^{24}$ 
Table 1. Volumes of acetonitrile and organic extract of tomato samples used in the dilution of deltamethrin solution at $500 \mu \mathrm{g} \mathrm{L}{ }^{-1}$ to obtain $5 \mathrm{~mL}$ of solution at $50 \mu \mathrm{g} \mathrm{L} \mathrm{L}^{-1}$

\begin{tabular}{|c|c|c|c|c|c|}
\hline & \multicolumn{5}{|c|}{ Volume / mL } \\
\hline & A1 & $\mathrm{A} 2$ & A3 & A4 & A5 \\
\hline Deltamethrin standard solution / $\left(500 \mu \mathrm{g} \mathrm{L}^{-1}\right)$ & 0.50 & 0.50 & 0.50 & 0.50 & 0.50 \\
\hline Matrix extract & 0.00 & 1.00 & 2.00 & 3.00 & 4.00 \\
\hline Acetonitrile & 4.50 & 3.50 & 2.50 & 1.50 & 0.50 \\
\hline Total & 5.00 & 5.00 & 5.00 & 5.00 & 5.00 \\
\hline
\end{tabular}

Spectrophotometric analysis of the extracts

The presence of coextractives in organic extracts was analyzed by spectrophotometry in the UV-Visible region (320-590 nm).

Response after the saturation of the chromatographic system

Using a GC-ECD equipped with a properly cleaned column and liner (Split, SPL 17), the GC saturation by tomato components in responses to the chlorpyrifos, $\lambda$-cyhalothrin, cypermethrin and deltamethrin was evaluated. A pesticide standard solution $\left(50 \mu \mathrm{g} \mathrm{L}^{-1}\right)$ was successively injected in the GC-ECD (five repetitions). The saturation of the chromatographic system was obtained with five successive injections of the organic extracts from pesticide-free tomato samples. The detector response, after GC saturation, was reassessed with five new successive injections of the same standard solution for the four pesticides in acetonitrile with concentrations of $50 \mu \mathrm{g} \mathrm{L}^{-1}$.

\section{Analytical curves}

Analytical curves were prepared using the internal standard method to evaluate the influence of matrix components on detector response. Two series of standard solutions containing the four pesticides at concentrations of $5,10,20,50,100,300$ and $500 \mu \mathrm{g} \mathrm{L}^{-1}$ were prepared. The first series was obtained by dilution of the working solution $\left(50 \mathrm{mg} \mathrm{L}^{-1}\right)$ containing the four pesticides in pure acetonitrile (twice). The second standard series was prepared by dilution of the same working solution in matrix extracts (twice) obtained from SLE-LTP of the pesticidefree hydroponic tomatoes. The two analytical curves (solvent and matrix) were statistically compared.

Effect of the variation in the deltamethrin concentration on the chlorpyrifos quantification

A series of standard solutions containing both chlorpyrifos and deltamethrin was prepared in pure acetonitrile. Chlorpyrifos concentration was set at $50 \mu \mathrm{g} \mathrm{L}^{-1}$, while deltamethrin concentration varied in a sequence of $5,10,20,50,100,300$ and $500 \mu \mathrm{g} \mathrm{L}{ }^{-1}$.

Effect of the matrix component quantities on the deltamethrin quantification

Five deltamethrin standard solutions at $50 \mu \mathrm{g} \mathrm{L} \mathrm{L}^{-1}$ were prepared by the dilution of the standard solution in acetonitrile at $500 \mu \mathrm{g} \mathrm{L}^{-1}$. The dilutions were obtained by adding different volumes of acetonitrile and organic extracts from the SLE-LTP of the tomato samples (A1 to A5) (Table 1).

\section{Results and Discussion}

\section{Spectrophotometric analysis of the extracts}

Organic extracts from tomato samples are rich in pigments such as lycopene and $\beta$-carotene. In addition to these, extracts can also contain significant amounts of phenolic compounds such as flavonoids. Spectrophotometric analysis of these organic extracts shows an absorption band in the region of 340-390 nm, corresponding to phenolic compounds and a band in the visible region of 440-480 nm, regarding absorption of carotenoids. ${ }^{21,22}$ Carotenoids have high molar masses, but can be degraded when heated above $150{ }^{\circ} \mathrm{C},{ }^{25}$ suggesting that the presence of phenolic compounds and of pigment degradation products in the chromatographic system may be responsible for the matrix effect.

Response after saturation of the chromatographic system

The matrix components can saturate the active sites of the liner, column or detector of gas chromatograph. Results obtained after saturation of the chromatographic system with successive injections of organic extracts of tomato (white) show a significant increase in the areas of pesticide standards in acetonitrile. Figure 2 shows the percent area increases that were attributed to the analyzed pesticides $\left(\%=\left[\left(\overline{\mathrm{A}}_{\text {after }}-\overline{\mathrm{A}}_{\text {before }}\right) / \overline{\mathrm{A}}_{\text {before }}\right] \times 100\right)$. 


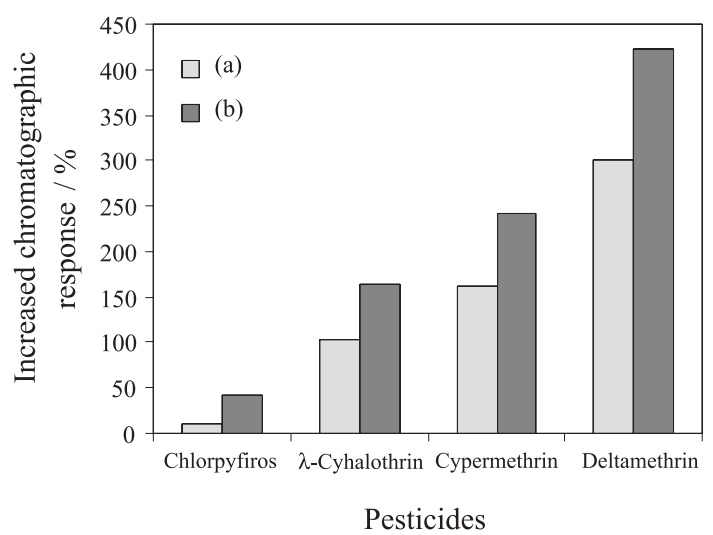

Figure 2. Percent increase in response attributed to pesticides $\left(50 \mu \mathrm{g} \mathrm{L} \mathrm{L}^{-1}\right)$ after chromatographic saturation with organic extracts of tomato samples: (a) using the internal standard and (b) absence of the internal standard for calculations.

The percent area increase of the four pesticides is associated with the retention time of these compounds (Figure 3) since the longer the retention time, the greater the matrix effect of each compound. It is worth emphasizing that the matrix effect (although minimized) is not eliminated by the internal standard method as the chromatographic response of deltamethrin showed an increase of about $300 \%$ in presence of the internal standard. The other pesticides also showed increase in the chromatographic response (chlorpyrifos $10 \%, \lambda$-cyhalothrin $103 \%$ and cypermethrin 162\%). According to Frenich et al., ${ }^{26}$ matrix molecules are retained in the active sites of the walls of the injector, leading to an increase in the amount of analyte molecules reaching the column, as well as the chromatographic response. However, the saturation of the chromatographic system (after 300 injections) with non-volatile compounds increases the number of active sites. This provokes a gradual decrease in the analyte response and in the analytical

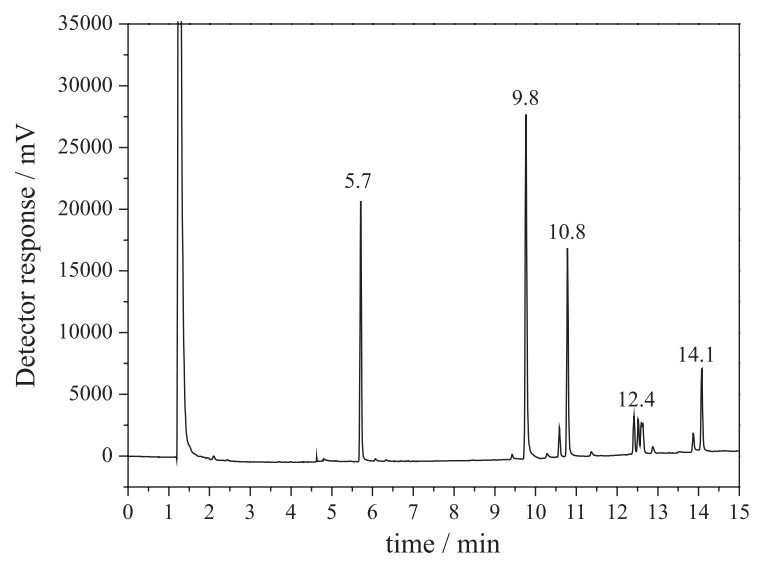

Figure 3. Chromatogram of pesticide standard solutions at $50 \mu \mathrm{g} \mathrm{L}{ }^{-1}$, where: $R_{t}=5.7 \mathrm{~min}$ for chlorpyrifos, $R_{t}=9.8 \mathrm{~min}$ for bifenthrin (internal standard), $R_{t}=10.8 \mathrm{~min}$ for $\lambda$-cyhalothrin, $R_{t}=12.4$ min for cypermethrin and $\mathrm{R}_{\mathrm{t}}=14.1 \mathrm{~min}$ for deltamethrin. resolution, so the linearity is affected and the sensitivity decreased with multiple injections. These effects depend on the type of matrix and analyte, as well as on the concentration level.

\section{Analytical curves}

Matrix effects can also be evaluated by comparing the analytical curves based on pesticide solutions prepared in pure solvents and in organic extracts obtained from the pesticide-free tomatoes (Figure 4).

Figure 4 shows the differences in the slopes between the two analytical curves for each pesticide, indicating a stronger matrix effect for pesticides with longer retention times. Chlorpyrifos underwent the smallest change in the chromatographic response when analyzed in pure solvent and in matrix extract, in agreement with the previous results. Amvrazi and Tsiropoulos ${ }^{27}$ also observed increased relative peak areas in tomato extracts by reproducing the positive effect of the matrix to all analyte studied.

When comparing the two analytical curves, if only the slope varies, the matrix components will contribute to introducing a proportional systematic error. On the other hand, if only the intercept varies, it signifies that there was a constant systematic error. ${ }^{27}$ To identify the type of error provided by the matrix components in this work, the ratios between the coefficients of the analytical curves in matrix extracts and in pure solvent were calculated (Table 2). Considering only the relationship among the angular coefficients (matrix/solvent), the chromatographic response increased by $27,46,100$ and $180 \%$ for chlorpyrifos, $\lambda$-cyhalothrin, cypermethrin and deltamethrin, respectively. The relationship among the linear coefficients (matrix/solvent) of the curves increased from 3, 43, 138 and $187 \%$ for the same pesticides, respectively. Although the matrix effect has a proportional systematic error and also a constant systematic error for the four pesticides, the proportional systematic error determines the increased response. This can be confirmed by the results shown in Figure 5, in which the percent increase of the chromatographic response was determined for the four pesticides $\left(\%=\left[\left(\overline{\mathrm{A}}_{\text {matrix }}-\overline{\mathrm{A}}_{\text {solvent }}\right) / \overline{\mathrm{A}}_{\text {solvent }}\right] \times 100\right)$. For the proportional error, the higher the pesticide concentration, the greater the difference between the pesticide area in pure solvent and in matrix extract, i.e., the greater is the amount of the pesticide adsorbed in the chromatographic system if analyzed in solvent. Another characteristic of the proportional error is that the calculated percentage of adsorbed pesticide tends to be constant in the concentration range evaluated. 

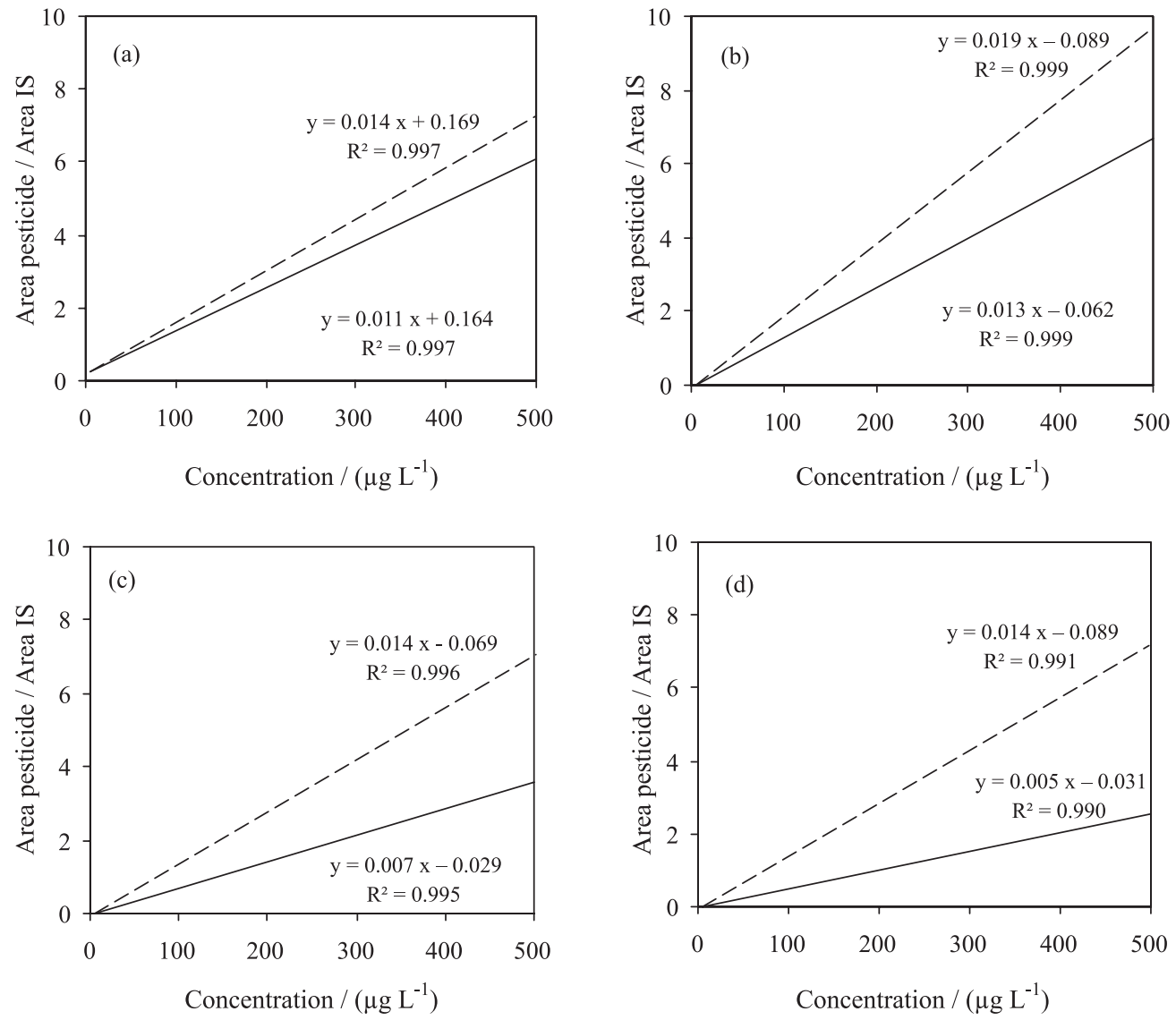

Figure 4. Analytical curves based on pesticide solutions prepared in acetonitrile (-) and in matrix extract (----): (a) chlorpyrifos, (b) $\lambda$-cyhalothrin, (c) cypermethrin and (d) deltamethrin.

Table 2. Ratio between slope coefficients and ratio between intercept coefficients of analytical curves for preparations in matrix extracts and in pure solvent. Comparison of calibration solvent with matrix using $F$-test

\begin{tabular}{lcccc}
\hline \multirow{2}{*}{ Pesticides } & \multicolumn{2}{c}{ Ratio between coefficients ${ }^{\mathrm{a}}$} & & $F_{\text {calc }}$ \\
\cline { 2 - 3 } \cline { 5 - 5 } & slope & intercept & & slope \\
\hline chlorpyrifos & 1.27 & 1.03 & & 59.05 \\
$\lambda$-cyhalothrin & 1.46 & 1.43 & & 791.70 \\
cypermethrin & 2.00 & 2.38 & & 491.74 \\
deltamethrin & 2.80 & 2.87 & & 499.49 \\
\hline
\end{tabular}

Ratio: matrix/solvent; $F_{\text {tab }}=4.26$ for the slopes.

The analysis of covariance (ANCOVA) $)^{12,28-30}$ was applied in order to certify the differences between slopes obtained in solvent and matrix extracts (Table 2). $F$ statistic was calculated $\left(F_{\text {calc }}\right)$ for comparing the slopes of each calibration curve (solvent and matrix) obtained for the pesticides. $F$ statistic was calculated as the quotient of the $\mathrm{S}_{\mathrm{N}}{ }^{2}$ and $\mathrm{S}_{\mathrm{D}}{ }^{2} \cdot \mathrm{S}_{\mathrm{N}}{ }^{2}$ is the variance due to the difference between the reduced and full variability of residuals and $\mathrm{S}_{\mathrm{D}}{ }^{2}$ is the full variability of residuals. $F$-calculated $\left(F_{\text {calc }}\right)$ were greater than the $F$-tabulated $\left(F_{\mathrm{tab}}\right)$ values, considering a $95 \%$ confidence level. It can be concluded that there is

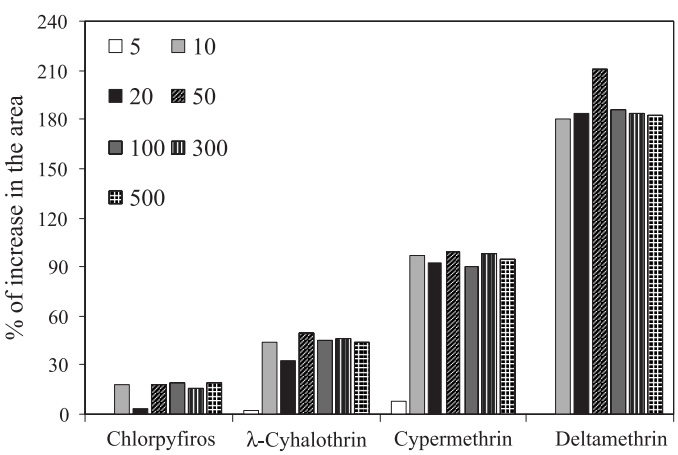

Pesticides

Figure 5. Percent increase in the chromatographic response of the pesticides chlorpyrifos, $\lambda$-cyhalothrin, cypermethrin and deltamethrin prepared in tomato extracts and acetonitrile. The concentrations of the pesticides were 5, 10, 20, 50, 100, 300 and $500 \mu \mathrm{g} \mathrm{L}{ }^{-1}$.

a significant difference between the two analytical curves (solvent and matrix).

Effect of the variation in the deltamethrin concentration on the chlorpyrifos quantification

To explain the low matrix effect of the organophosphate pesticide, the possibility of pyrethroid (specifically 
deltamethrin) to act as a protective analyte for chlorpyrifos during analysis of standard solutions was studied in full detail. The competition between chlorpyrifos and deltamethrin for GC adsorption sites was evaluated by fixing the chlorpyrifos concentration and varying deltamethrin concentration. Deltamethrin has no influence on chlorpyrifos adsorption in the chromatographic system because the mean peak areas of chlorpyrifos at $50 \mu \mathrm{g} \mathrm{L}^{-1}$ are not significantly different, regardless of the deltamethrin concentration in the standard solution ( 5 to $500 \mu \mathrm{g} \mathrm{L}^{-1}$ ). No work in the literature has studied the competition between the pesticides by active sites of the chromatographic system.

\section{Effect of the matrix component quantities on the deltamethrin quantification}

The deltamethrin adsorption was evaluated at a fixed concentration $\left(50 \mu \mathrm{g} \mathrm{L}^{-1}\right)$ with different amounts of matrix extracts. These constituents, mainly carotenoids, have high molar masses and there is a clear competition between deltamethrin and matrix components for GC active sites (Figure 6).

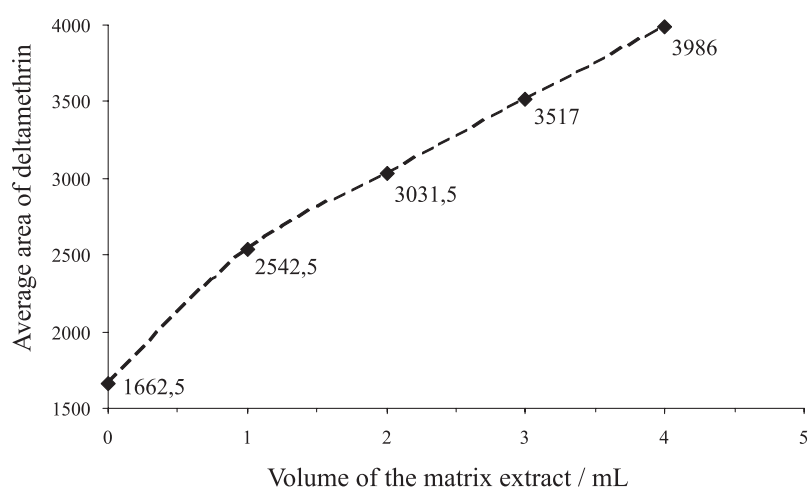

Figure 6. Chromatographic response of deltamethrin at $50 \mu \mathrm{g} \mathrm{L} \mathrm{L}^{-1}$ to different amounts of matrix extracts $(0,1,2,3$ and $4 \mathrm{~mL}$ of organic tomato extract).

The addition of the first volume $(1 \mathrm{~mL})$ of extract containing matrix extracts causes a larger variation in the deltamethrin peak area, i.e., the competition for sites is more intense. On the other hand, the analysis with the addition of larger extract volumes causes an increase in the constant response. Recent work has suggested the dilution of the samples to reduce the amount of matrix injected into the system, consequently, decreasing the matrix effects, expanding the possibility to perform quantification with solvent based standards. However, the efficiency of simple sample dilution is often limited, in particular by the limit of detection of the method and can significantly vary from matrix to matrix. ${ }^{31,32}$

\section{Conclusions}

The pesticide analysis in organic extracts of tomato prepared by SLE-LTP showed interference of coextractives. Endogenous tomato components present in the extracts increased the chromatographic response, mainly of pyrethroids (chlorpyrifos $<\lambda$-cyhalothrin $<$ cypermethrin $<$ deltamethrin). It was also found that the internal standard minimizes but does not eliminate this effect and that there is no competition for the liner active sites among the pesticides.

The matrix introduce a proportional systematic error in the concentration range ( 5 to $500 \mu \mathrm{g} \mathrm{L} \mathrm{L}^{-1}$ ), as the difference between the peak area of pesticides prepared in organic extract and in pure solvent increases with increase in concentration.

Further studies to investigate the adsorption of other pesticides in gas chromatographic injectors and columns are still required to explain the relationship between retention time and matrix effect.

\section{Supplementary Information}

Supplementary data are available free of charge at http://jbcs.sbq.org.br as pdf file.

\section{Acknowledgements}

The authors wish to thank the following Brazilian agencies: Conselho Nacional de Desenvolvimento Científico e Tecnológico (CNPq) and Fundação de Amparo à Pesquisa do Estado de Minas Gerais (FAPEMIG) for their financial supports.

\section{References}

1. Cooper, J.; Dobson, H.; Crop Prot. 2007, 26, 1337.

2. Lourencetti, C.; Marchi, M. R. R.; Ribeiro, M. L.; Talanta 2008, 77, 701 .

3. Goulart, S. M.; Queiroz, M. E. L. R.; Neves, A. A.; Queiroz, J. H.; Talanta 2008, 75, 1320.

4. Agência Nacional de Vigilância Sanitária (ANVISA); Monographs, Brasil, 2011, http://www.anvisa.gov.br accessed in August 2011.

5. Codex Alimentarium Commission: Food and Agricultural Organization of the United Nations (FAO) / World health organization (WHO); Pesticide Residues in Food, Maximum Residue Limits (MRL's), 2011, http://www.codexalimentarius.net accessed in August 2011.

6. Van der Hoff, G. R.; Van Zoonen, P.; J. Chromatogr., A 1999, 843,301 . 
7. Sanchez-Brunete, C.; Albero, B.; Martín, G.; Tadeo, J. L.; Anal. Sci. 2005, 21, 129.

8. Hajslová, J.; Holadova, K.; Kocourek, V.; Poustka, J.; Godula, M.; Cuhra, P.; Kempny, M.; J. Chromatogr., A 1998, 800, 283.

9. Salvador, M.; Frenich, A. G.; González, F. J. E.; Vidal, M.; Chromatographia 2006, 64, 667.

10. Erney, D. R.; Gillespie, A. M.; Gilvydis, D. M.; J. Chromatogr., A 1993, 638, 57.

11. Schenck, F. J.; Lehotay, S. J.; J. Chromatogr., A 2000, 868, 51.

12. González, F. J. E.; Torres, M. E. H.; López, E. A.; Cuadros-Rodriguez, L.; Vidal, J. L. M.; J. Chromatogr., A 2002, 966, 155.

13. Hajslová, J.; Zrostlikova, J.; J. Chromatogr., A 2003, 1000, 181.

14. Poole, C. F.; J. Chromatogr., A 2007, 1158, 241.

15. Przybylski, C.; Hommet, F.; J. Chromatogr., A 2008, 1201, 78.

16. Frenich,A. G.; Vidal, J. L. M.; Moreno, J. L. F.; Romero-González, R.; J. Chromatogr., A 2009, 1216, 4798.

17. Pinho, G. P.; Neves, A. A.; Queiroz, M. E. L. R.; Silvério, F. O.; Starling, M. A. V. M.; Quim. Nova 2010, 33, 909.

18. Gobo, A. B.; Kurz, M. H. S.; Pizzutti, I. R.; Adaime, M. B.; Zanella, R.; J. Braz. Chem. Soc. 2004, 15, 945.

19. Menkissoglu-Spiroudi, U.; Fotopoulou, A.; Int. J. Environ. Anal. Chem. 2004, 84, 15.

20. Moraes, S. L.; Rezende, M. O. O.; Nakagawa, L. E.; Luchini, L. C.; Quim. Nova 2002, 25, 196.

21. Simonetti, P.; Gardana, C.; Riso, P.; Mauri, P.; Pietta, P.; Porrini, M.; Nutr. Res. 2005, 25, 717.
22. Lenucci, M. S.; Cadinu, D.; Taurino, M.; Piro, G.; Dalessandro, G.; J. Agric. Food Chem. 2006, 54, 2606.

23. Pinho, G. P.; Neves, A. A.; Queiroz, M. E. L. R.; Quim. Nova 2009, 32, 987.

24. Pinho, G. P.; Neves, A. A.; Queiroz, M. E. L. R.; Silvério, F. O.; Food Chem. 2009, 121, 251.

25. Pérez-Galvez, A.; Rios, J. J.; Minguez-Mosquera, M. I.; J. Agric. Food Chem. 2005, 53, 4820.

26. Frenich,A. G.; Vidal, J. L. M.; Moreno, J.L. F.; Romero-González. R.; J. Chromatogr., A 2009, 1216, 4798.

27. Amvrazi, E. G.; Tsiropoulos, N. G.; J. Chromatogr., A 2009, 1216, 2789.

28. Cuadros-Rodriguez, L.; García-Campana,A. M.;Almansa-López, E.; Egea-Gonzáles, F. J.; Cano, M. L. C.; Frenich, A. G.; Marínez-Vidal, J. L.; Anal. Chim. Acta 2003, 478, 281.

29. Sanchez-Brunete, C.; Albero, B.; Martín, G.; Tadeo, J. L.; Anal. Sci. 2005, 21, 129.

30. Torres, M. E. H.; Egea Gonzalez, F. J.; Cuadros-Rodriguez, L.; Lopez, E. A.; Vidal, J. L. M.; Chromatographia 2003, 57, 657.

31. Ferrer, C.; Martínez-Bueno, M. J.; Lozano, A.; Fernández-Alba, A. R; Talanta 2011, 83, 1561.

32. Kruve, A.; Leito, I.; Herodes, K.; Anal. Chim. Acta 2009, 651, 75 .

Submitted: May 16, 2011

Published online: December 1, 2011 